\title{
Demographic Structure of a Primitive Population: A Simulation ${ }^{1}$
}

\author{
JEAN W, MACCLUER, 2 JAMES V, NEEL AND \\ NAPOLEON A. CHAGNON \\ Department of Human Genetics, University of Michigan, \\ Ann Arbor, Michigan
}

\begin{abstract}
A stochastic computer simulation model has been used to study the demography of the Yagnomamö Indians of Venezuela and Brazil, whose social organization is typical of many primitive societies. It has been found by simulation that perhaps one third of all Yạnomamö marriages involve individuals related as first or second cousins, and that more than $16 \%$ of all males must leave their villages to find wives, in spite of a strong preference for village endogamy. In the process of validating and experimenting with the model, we discovered (1) the role of sibship size in determining a man's ability to obtain wives; (2) the variability in frequency of cousin marriages through time; and (3) the importance of wife trading in assuring that few men complete the reproductive period without having married at least once. In addition, we strengthened our impressions, gathered from ethnographic data, that the Yạnomamö are an expanding population.
\end{abstract}

Primitive population demography is a discipline which combines the field observations of the anthropologist with the analytical methods of the demographer. Unfortunately, traditional demographic techniques, generally intended for use with large, literate populations, are often inappropriate when applied to small, technologically primitive ones. Methods are needed for estimating demographic parameters in populations which do not have written histories, counting systems, or calendars.

A promising technique which, however, has not been adequately exploited in the study of primitive populations is computer simulation. There have been a number of demographic simulation studies aimed primarily at large, modern populations, e.g., Orcutt et al. ('61), Hyrenius ('64 et seq.), Beshers ('67), Jacquard ('67, '70), Perrin and Sheps ('64), Jain ('68), and Heer and Smith ('68, '69). Other computer models have been developed whose major purpose is to study the genetic composition of human populations, e.g., Brues ('63), Schull and Levin ('64), Williams ('65), Cavalli-Sforza ('69), Cavalli-Sforza and Zei ('67), Levin ('67), Livingstone ('69), Morgan ('69), Hainline ('63), Anderson and King ('70), and King and Ander- son (71). Most of these models include certain elements of demographic structure, and some may be applied to nonhuman, age-structured populations. However, the use of computer simulation in anthropology to supplement field observations on small populations has been limited: Kunstadter et al. ('63), Gilbert and Hammel ('66).

MacCluer ('67) developed a general model which simulates the genetic and demographic characteristics of a small, modern human population, and applied it to the estimation of frequencies of consanguineous marriage and rate of accumulation of inbreeding in a small Japanese island population (MacCluer and Schull, '70a), and to the estimation of the ratio of effective population size to census size (MacCluer and Schull, '70b). Dyke (68) has used this model to obtain preliminary estimates of sex- and age-specific mortality rates in the Northside French population of St. Thomas, Virgin Islands. Following the same strategy used in this model, we have now developed a stochastic computer simulation model of a primi-

This work has been supported in part by grant AT(11-1)-1552 of the U. S. Atomic Energy Commission.

2 Present Address: Department of Anthropology, The Pennsylvania State University, University Park, Pennsylvania. 
tive population, the Yanomamö Indians of Venezuela and Brazil, whose social organization is typical of many primitive societies. The purpose of this report is to describe the model and to illustrate the manner in which we are using it (1) to check field data for consistency and indicate areas in which more data are needed, and (2) to study demographic structure. We shall also try to indicate some of the practical problems which arise when the data base is weak and the population structure complex.

\section{THE POPULATION}

The Yanomamö Indians are a tribe of tropical forest slash-and-burn cultivators inhabiting southern Venezuela and northern Brazil. The population of 10,000 to 15,000 is divided into approximately 125 villages ranging in size from 40 to 250 , many of which have yet to be contacted (Chagnon, '68b). There exist complex networks of biological relationship between villages as a result of wife exchange, village fissioning, and changing patterns of alliances associated with inter-village warfare (Chagnon, '68a). A high proportion of the mortality can be attributed to warfare and infanticide, the latter most often involving females. There are differences from region to region in warfare intensity (Chagnon, '68c) and in demographic properties; this report is based largely on data collected in the central area of the tribe (Chagnon, '68a,c).

The Yạnomamö have an Iroquois kinship system (i.e., siblings and parallel cousins are terminologically equivalent but distinguished from cross cousins), and a prescriptive bilateral cross-cousin marriage rule. Social status in this society is largely determined by the kinship system. Insofar as marriage is a socio-biological event, it is governed mainly by kinship relationships. Thus, men define all women into six primary categories (Chagnon, '66, '68a). It is incestuous to marry women who belong to five of the six categories, although the taboo is occasionally broken. The sixth, marriageable category consists of women related to the man as mother's brother's daughter (MoBroDa) and father's sister's daughter (FaSisDa). Within each generation, however, all the males and females of one lineage call each other "brother" and "sister." Thus, a woman who is classified as MoBroDa or FaSisDa, and is therefore among a man's marriageable relatives, may actually be only distantly related to him biologically. Polygyny is common, especially among headmen, with additional wives frequently being chosen from among the sisters of the first wife. The Ya̧nomamö feel obligated to reciprocate women to the kinship group from which they obtain their wives. Because it is considered desirable to form alliances with the most powerful lineages, such lineages are always in a good position to obtain women. As a result of female infanticide and polygyny, women are in short supply, so that many men are forced to remain bachelors or to obtain women by raiding other villages (which, of course, only increases the shortage in the raided village). Young girls are often married many years before they reach maturity and no woman remains unmarried for very long after she has had her first menses or has been widowed or separated. Most of the friction within villages and much of the inter-village hostility can be attributed directly to the shortage of women.

Yanomamö women begin to reproduce at about age 15. Women who survive to age 40 report, on the average, about 3.8 livebirths, with an average livebirth interval of three or four years (Neel and Chagnon, '68). [We suspect that there is gross underreporting of those livebirths following which the child is not permitted to live, i.e., is subjected to infanticide (cf. Neel and Chagnon, '68).] Thus far it has been impossible to obtain quantitatively accurate data on the frequency of infanticide, but to a first approximation, the average woman living to age 40 is thought to have borne 4.5 children. The rather long interval between births can be attributed to induced abortion and avoidance of sexual intercourse for 12 to 18 months following childbirth. The average number of children surviving to maturity for each woman who survives to age 40 is about 3.2 . As a result of polygyny, there is much greater variability in the number of offspring born to males than in the number born to females.

We have chosen for this study four villages located along the course of the 
Upper Orinoco River and one of its principal tributaries, the Mavaca River, in southern Venezuela. The four villages, Ora-teri, Koro-teri, Monou-teri, and Patanowa-teri, have a common origin (Chagnon, '66, '68b) and are closely related biologically, as revealed by pedigrees and by genetic networks based on blood group and serum protein gene frequencies (Ward, '70). The populations of the four villages were $86,50,71$, and 244 , respectively at the time of the study. Data collection was done in two different field trips, the first three villages being visited in 1966 and the fourth in 1968. A preliminary account of some of the demographic findings is to be found in Neel and Chagnon ('68). Ideally, a demographic survey should be conducted instantaneously, at a single point in time. Failing this, one should collect the data in as short a time interval as possible, to insure comparability of information across all segments of the population. However, since it has been impossible to visit more than a few villages in a single trip, the period of time required to conduct a census is necessarily rather long. While we recognize the possible biases introduced in combining data collected over a period of two years, we have elected to treat the four villages as a single population. The age and sex distribution for the combined population of 451 is given in figure 1 . The deficiency of both males and females in the age group 10 to 19 is probably attributable to the introduction of $P$. falciparum malaria into the area about 15 years ago, with the well known particularly heavy toll in infants. Most members of this population belong to one of eleven lineages (descent is patrilineal), with most lineages being represented in several villages (see table 1). The two politically most significant lineages, 1 and 2 , contain about $63 \%$ of the population of the four villages. For a more detailed description of the Yanomamö socio-political organization, see Chagnon ('66, 68a,b,c).

\section{THE MODEL}

A simulation begins with a catalog of members of the four Yanomamö villages, each person characterized by sex, estimated birth (and death) date, marital status, lineage, village, and relationship to other members of the population, specifically the identifying numbers of his parents, grandparents, and great-grandparents (if known). Number of offspring is recorded for females. Also recorded is the MN blood group genotype for each individual, although this variable is not relevant to the present discussion. Yearly changes in the composition of this initial population are simulated as individuals marry, reproduce and die according to age- and sex-specific probabilities estimated from field data. The real population is eventually replaced by an entirely artificial one created during the course of the simulation, a population whose characteristics are determined by the input conditions and which can be analyzed in far greater detail than can the real population from which it was derived. The probabilities of vital events are assumed to remain constant through time. Although feedback mechanisms, in the form of changing vital rates, may operate to keep population sizes within certain limits, the assumption of constancy of vital rates seems reasonable as a first approximation, and allows us to make certain comparisons with the predictions of theoretical models. A simplified flowchart of the program, which was written in a modified FORTRAN IV for the IBM 1130, is shown in figure 2 , and the required input is listed in table 2 .

The strategy in our simulation study has been to build a model which behaves as nearly as possible like the real population. We recognize, of course, that there may be more than one model which accounts for the data. However, at this

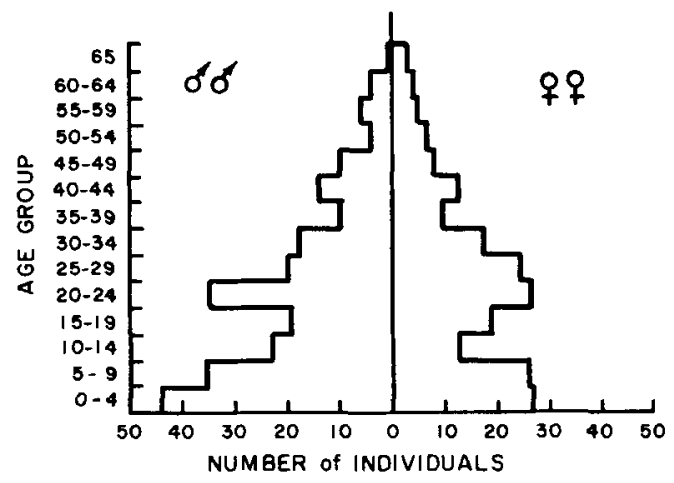

Fig. 1 Age-sex distribution for four Yanomamỏ villages. 
TABLE 1

Population of four Yạnomamö villages by lineage

\begin{tabular}{|c|c|c|c|c|c|c|c|c|c|c|c|c|c|}
\hline \multirow{2}{*}{ Village } & \multicolumn{12}{|c|}{ Lineage } & \\
\hline & 1 & 2 & 3 & 4 & 5 & 6 & 7 & 8 & 9 & 10 & 11 & Unknown & \\
\hline 1 & 14 & 24 & 8 & 0 & 17 & 4 & 0 & 2 & 2 & 0 & 1 & 14 & 86 \\
\hline 2 & 4 & 17 & 0 & 12 & 4 & 4 & 0 & 0 & 1 & 4 & 2 & 2 & 50 \\
\hline 3 & 23 & 24 & 0 & 0 & 7 & 4 & 1 & 3 & 6 & 1 & 0 & 2 & 71 \\
\hline \multirow[t]{2}{*}{4} & 98 & 81 & 30 & 0 & 0 & 2 & 5 & 4 & 8 & 0 & 0 & 16 & 244 \\
\hline & 139 & 146 & 38 & 12 & 28 & 14 & 6 & 9 & 17 & 5 & 3 & 34 & 451 \\
\hline
\end{tabular}

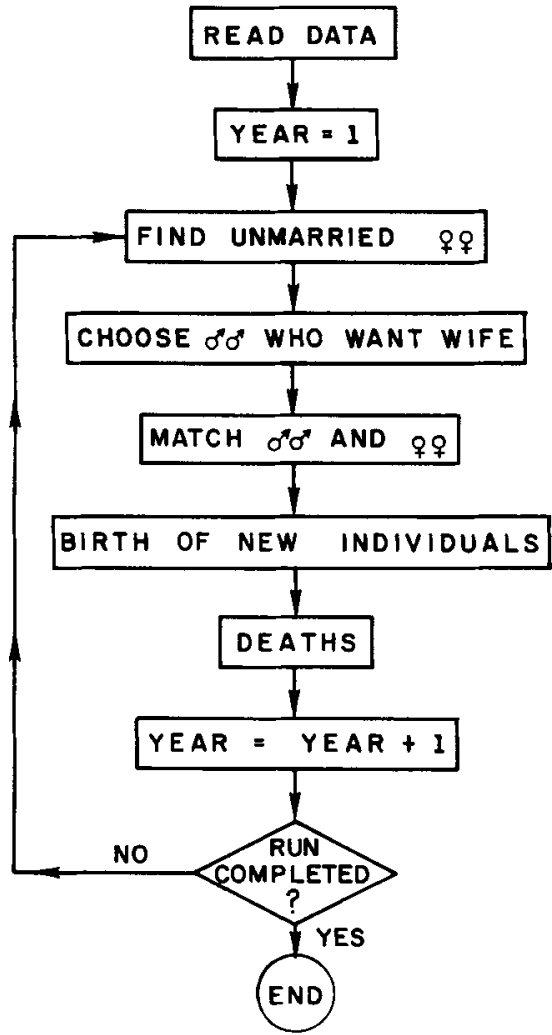

Fig. 2 Simplified flow chart of the simulation program.

point in the study, we have elected to accept, tentatively, a model as being "correct" if (1) its assumptions are consistent with our knowledge of the population and (2) the resulting artificial populations correspond to the real in certain demographic characteristics to be discussed below. With this strategy, whenever there are discrepancies between the characteristics of model and actual data, one assumes that his impressions about the way the population behaves are in correct, and the model must be modified. On the basis of knowledge of the population, one attempts to determine what assumption of the model is likely to be at fault, modifies the model, and tries again. As the model evolves, knowledge of the behavior of the population improves provided that the model is used properly, i.e., to suggest elements of population structure which have been overlooked. No change is introduced into the model unless it can be justified by the data. (Fortunately, in our simulations the model produced generally satisfactory agreement with the field-estimated parameters in most instances; except as indicated below, "juggling" was unnecessary). When one reaches the point at which model and population are similar with respect to the chosen demographic characteristics, then one makes inferences from the model about other aspects of the behavior of the real population which may not be apparent from examination of the data, for example, because of lack of time depth or small population size.

It is important to make clear the tenuous nature of the input data as compared, for example, with that available for a large, civilized population. Firstly, because of lack of written records, failure of recall, or deliberate concealment, there is room for considerable uncertainty with regard to the facts in these four villages. Secondly, as will become apparent later, in a small population such as this, there may be considerable temporal variation in the input parameters. Moreover, we found it necessary to introduce a few simplifying assumptions into the model. Probably the most unrealistic assumption was that this cluster of four villages remained discrete and self-contained for 200 years, 
TABLE 2

Simulation input

\begin{tabular}{lc}
\hline \multicolumn{1}{c}{ Information on each individual } & Vital rates and other input parameters \\
\hline Person & Probabilities of \\
Father & Dying (Males, Females) \\
Mother & Reproducing (Females) \\
Date of birth & Mating (Males) \\
$\begin{array}{l}\text { Dead or alive? } \\
\text { Village in which now residing }\end{array}$ & by age and genotype \\
Marital status & \\
Lineage & Lineage and village preferences for mating \\
Number of births (for females) & Age preferences for mating \\
\hline
\end{tabular}

not engaging in the fission-fusion process which characterizes Yạnomamö village relationships.

\section{Estimation of input parameters}

Preliminary estimates of the vital rates required as input for the model were made from observations of the four villages during the five-year period 1964 through 1968. Because the number of vital events occurring in any one year was so small, we found it necessary to combine the figures for several years in order to obtain reliable estimates. For example, the probability of reproducing for married females age $x$ was found by dividing the number of births in 19641968 in which the mother was age $x$, by the total number of married women age $x$ during those five years. Because there were so few females of some ages, we computed probabilities for women by fiveyear age groups. Similarly, probabilities of mating for males were calculated from marriages during 1964-1968. For a male age $x$ with $n$ wives, the probability of looking for his $(n+1)$ st wife in a given year is

$\operatorname{PMATE}(x, n)=$

$$
\frac{\text { marriages of males age } x \text { with } n \text { wives }}{\text { total number of males age } x \text { with } n \text { wives }}
$$

Probabilities for first and second wives were computed from this formula for males in five-year age groups. Probabilities for third and fourth wives were assumed to be constant from age 30 on, i.e., they were computed from one twenty-year age group, for males age 30 to 50 . It was assumed that no man could have more than four wives at a time, nor could he marry when he was older than age 50 , these assumptions being guided by known marriage behavior.

Age-specific probabilities of dying had to be estimated indirectly, since there are no reliable figures on age at death for the Yạnomamö. From impressions gathered in the field, it was estimated that during the first year of life, $25 \%$ of males and $35 \%$ of females fail to survive. Perhaps $15 \%$ of newborn males and females die of natural causes in the first year of life, with infanticide being responsible for the deaths of an additional $10 \%$ of males and $20 \%$ of females. It was estimated that another $10 \%$ of males and females die before maturity (age 15) and that only $20 \%$ of males survive beyond age 50 , and $25 \%$ of females beyond age 40 . In order to compute death probabilities for each age, we had to specify a shape for the mortality curve. The available data are best fitted by the curve in figure 3 , which is the approximate shape of the mortality curves in a number of populations (Coale and Demeny, '66). From the expression for the probability of dying between ages $i$ and $j(j>i)$,

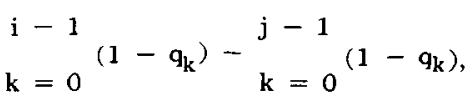

it was possible to solve for $\mathrm{q}_{\mathrm{x}}$, the probability of dying at age $x$, given only the percentages stated above.

Other input included a set of variables specifying the pattern of mate selection for males, i.e., preferences with respect to age, lineage, and village of potential wife. It was estimated that men prefer 


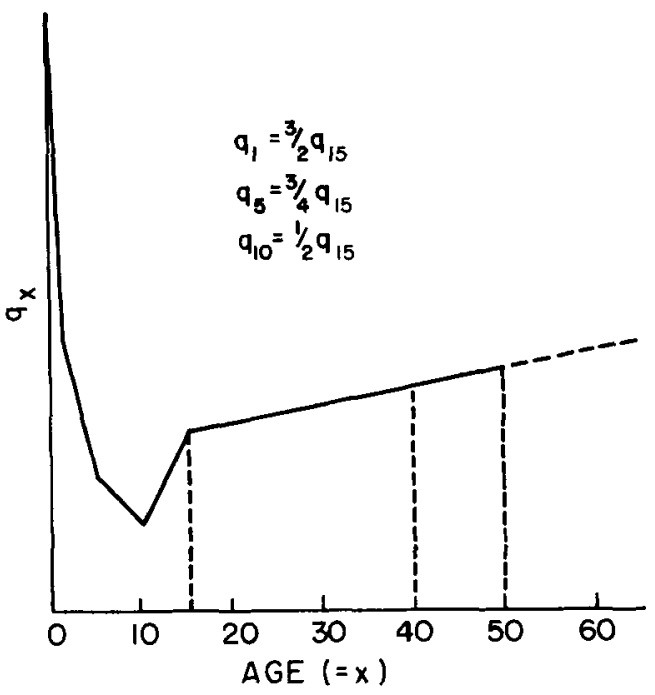

Fig. 3 Model mortality curve. $\mathrm{q}_{x}$, probability of dying at age $x$ for an individual who has survived to age $x-1$.

wives who are on the average seven years younger than they are. Lineage preferences were specified in an array LIN, where $\operatorname{LIN}(i, j)$ is the $j$ th choice lineage for a male of lineage $i$. Thus, by setting $\operatorname{LIN}(2,1)=3$, we are specifying that males from lineage 2 look for wives first among females of lineage 3 . This array may be different for each village, although we have assumed that all villages have the same pattern of lineage preferences. Lineage exogamy is required. Village preferences for wives are specified in a similar way, with $\operatorname{VILL}(i, j)$ being the $j^{\text {th }}$ choice village for a male of village $i$. Since village endogamy is preferred, $\operatorname{VILL}(i, 1)=i$. The arrays of lineage and village preferences are allowed to change during the course of a simulation, as various lineages and villages change in size (and therefore in political power and in desirability as sources of wives).

Other required input (table 2) include variables specifying length of the simulation run in years, limits of the reproductive period (15 to 65 for males, 15 to 40 for females), sex ratio at birth (0.500), maximum number of births for females (15), maximum number of wives per male at a given time, and a set of parameters controlling type of output and allowing simulation runs to be interrupted and restarted.

\section{The program}

A simulation run begins with the reading of the initial population, the vital rates, the arrays of mate preferences, and the other input parameters (see fig. 2). A year of simulation begins with mating. An array is formed of unmarried females between the ages of 11 and 40, arranged by village. Every unmarried female within the appropriate age range is entered in the list. In a second array are entered the males who will look for wives in the current year. The decision as to whether a male age $x$ with $n$ wives will be entered in this array is made as follows: A random number $r$ is generated (from a uniform distribution between zero and one) and compared with $\operatorname{PMATE}(x, n)$, the probability of looking for a mate for a male age $x$ with $n$ wives. If $0 \leqslant r \leqslant \operatorname{PMATE}(x, n)$, then the male is entered in the array; if $\operatorname{PMATE}(x, n)<r \leqslant 1$, he is not. All decisions concerning vital events are made in a similar way. The marriageable ages for males are 15 to 50; widowers with no wives have the same probability of marrying as single males of the same age. As stated earlier, because of the small numbers of males of some ages, values of PMATE were computed on the basis of five-year age groups. The effect of this grouping is to reduce slightly the variance in age at marriage for males.

Next the male array is rearranged in the order in which males will search for wives. Because of the shortage of women, there are usually many more men searching for wives than there are women available; therefore the order in which the males are chosen to search is important. This reordering of the male array is a good example of the way in which the model has evolved: initially, the males were ordered randomly, i.e., without respect to their age or other characteristics. But since it would be expected that males in sibships already involved in marriagebased alliances would be in a more favorable position to get wives, it was decided to move all such males to the top of the list. In a final modification, males were also given priority on the basis of the number of children their fathers had, this criterion taking precedence over that based on marriage alliances. The justifi- 
cation for this procedure will be given later.

Marriage consists in matching members of the male and female lists. Each male in turn searches first within his own village, and then in the other villages according to the specified search pattern. When a wife is found, the male's marital status is changed accordingly and his identifying number is entered in the array of information associated with his wife. Initially, each male followed the specified pattern of lineage preference within each village in which he was searching. Within a given village and lineage, all the available females were arranged in order, the females closest to the desired age difference appearing at the top of the list. The male chose the female closest to the ideal age. Thus, the three criteria involved in mate selection were village, lineage, and age, with age being the least important. The one exception to this statement arose in the case of males whose sibships were involved in alliances; such males always look first in the sibship with which the alliance exists. This feature of the model has another consequence: if a male is looking for a second or subsequent wife, he looks first in the sibship of his first wife, thus providing for sororal polygyny and giving the males involved an advantage in finding wives. Although in reality, Ya̧nomamö males sometimes separate from their wives, marriages in the artificial population last as long as both spouses are alive; both sexes are allowed to remarry upon the death of a spouse. If a male marries a woman from another village, she comes to his village to live; this is the only form of migration allowed.

In reaching the "final" program, the general model thus far described was then modified in order to render output more consistent with field observations. First, in order to increase the simulated proportion of married males in the younger age groups to the level observed in the real population, we set $\operatorname{PMATE}(x, 0)=1$ for all $x$, i.e., each unmarried adult male was allowed to look for a mate regardless of his age, and he married as soon as an appropriate female was available. Second, in an attempt to increase the proportion of marriages between first cousins to a level consistent with that observed in the four villages, males were required to look for wives first among their cross cousins. This modification will be discussed in greater detail in the next section. A final modification in the mating structure of the artificial population concerned the preference for village endogamy. If males were allowed to search in other villages as soon as they had failed to find a wife in their own village, then the frequency of village exogamy in the artificial population became much too high. To simulate the strong preference of the Yanomamö for village endogamy, we stipulated that males could not marry outside their village until age 25, females until age 15 .

The next portion of the program is concerned with reproduction. The decision as to whether a female will reproduce is a function primarily of her age, the reproductive period being restricted to ages 15 to 40 . To simulate the effects of abortion and avoidance of intercourse following childbirth in increasing birth intervals in the real population, we required that birth intervals be at least two years. Agespecific probabilities of reproducing were adjusted accordingly, so that the numbers of births to women of each age group would continue to match the observed distribution. Reproduction is limited mostly to married females; however, in keeping with estimates made from field data, there is a $10 \%$ probability of nonpaternity, i.e., that the father of the child will be a man other than the woman's current husband. In each case, the father of the child is chosen from among 25 to 40 year old males in the woman's village and according to the lineage preferences established for mating. Unmarried women also have a certain probability of reproducing, equal to the probability of nonpaternity multiplied by the age-specific probability of reproducing. Thus, a married woman of age $x$ is ten times as likely to reproduce as an unmarried woman of the same age; but one-tenth of the married woman's children will have fathers other than the woman's husband. A male's fertility is limited only by the fertility of his wives and does not depend directly upon his age. This assumption of the model may be an oversimplification, but we have no data upon which to base 
a modification. Each time a woman reproduces, the characteristics of the offspring are determined: he is given an identification number and assigned to his father's lineage and village, and his sex is decided on the basis of the specified sex ratio.

The final section of the program is concerned with survival. Deaths occur according to the mortality functions mentioned earlier; no individual lives beyond age 65 . When a person dies, his date of death is recorded, and all information about him is retained in storage so that subsequent analyses can be done.

The processes of mating, birth and death are repeated for the specified number of years, and the run is terminated. Because many of the decisions are stochastic, it is possible to do series of runs under the same initial conditions simply by varying the initial random number, and thus to get some idea of the stability of various parameters.

The validity of the simulation results depends of course, not only on the assumptions of the model, but on the characteristics of the random number generator. We tested several random number generators, including RANDU, the subroutine furnished in the IBM Scientific Subroutine Package. We found RANDU to be unsatisfactory (MacCluer and Dyke, unpublished), primarily because of the short cycle time (only about 8000 random numbers on the IBM 1130). We chose instead a subroutine which uses the multiplicative congruential method (this subroutine, known as FRAND, was written by Mr. Thomas Plum of the Logic of Computers Group, University of Michigan) and which has a cycle time in excess of $4 \times 10^{6}$.

\section{RESULTS}

\section{Demographic analysis}

Demographic analyses for the artificial populations were done from the information stored for each individual during the course of a run. As shown in tables 2 and 3 , much more is known about members of the artificial populations than about individuals in the initial, real population. Table 4 gives a comparison of a number of demographic characteristics of the four Yanomamö villages and of artificial populations generated in fifteen 200-year runs of the simulation program. The population sizes for these 15 runs, each of which began with 451 individuals, varied between 293 and 1121 at the end of 200 years. Thus, there is a fourfold difference between the minimum and maximum population sizes, even though all the artificial populations experienced the same underlying vital rates. The annual growth rates for the artificial populations were computed from the compound interest formula

$$
\mathrm{N}_{200}=\mathrm{N}_{\mathrm{o}}(1+\mathrm{r})^{200}
$$

where $N_{0}$ is the initial population size, $N_{200}$ is the size after 200 years, and $\mathrm{r}$ is the growth rate. The range in yearly growth rates was -0.0022 to 0.0045 , with an average of 0.0009 . Unfortunately, two artificial populations grew so fast that they exceeded the capacity of the computer, and these runs had to be discarded; therefore the actual population growth rate is probably somewhat greater than the mean for the 15 artificial populations included in this analysis.

A standard measure of the growth rate in a demographically stable population is

\section{TABLE 3}

Simulation output: information on each individual

Person

Father

Mother

Date of birth

Date of death or emigration

Village in which now residing

Village of birth

village in which last resided

Marital status

Lineage

Age at first marriage

Alliance with another sibship

Ages of father and mother at birth

Parity

Interval since birth of older sib

Number of births

Number of offspring who die before Females maturity

Interval since last birth

Genotype

Inbreeding coefficient 
TABLE 4

Comparison of demographic characteristics in the real and artificial populations

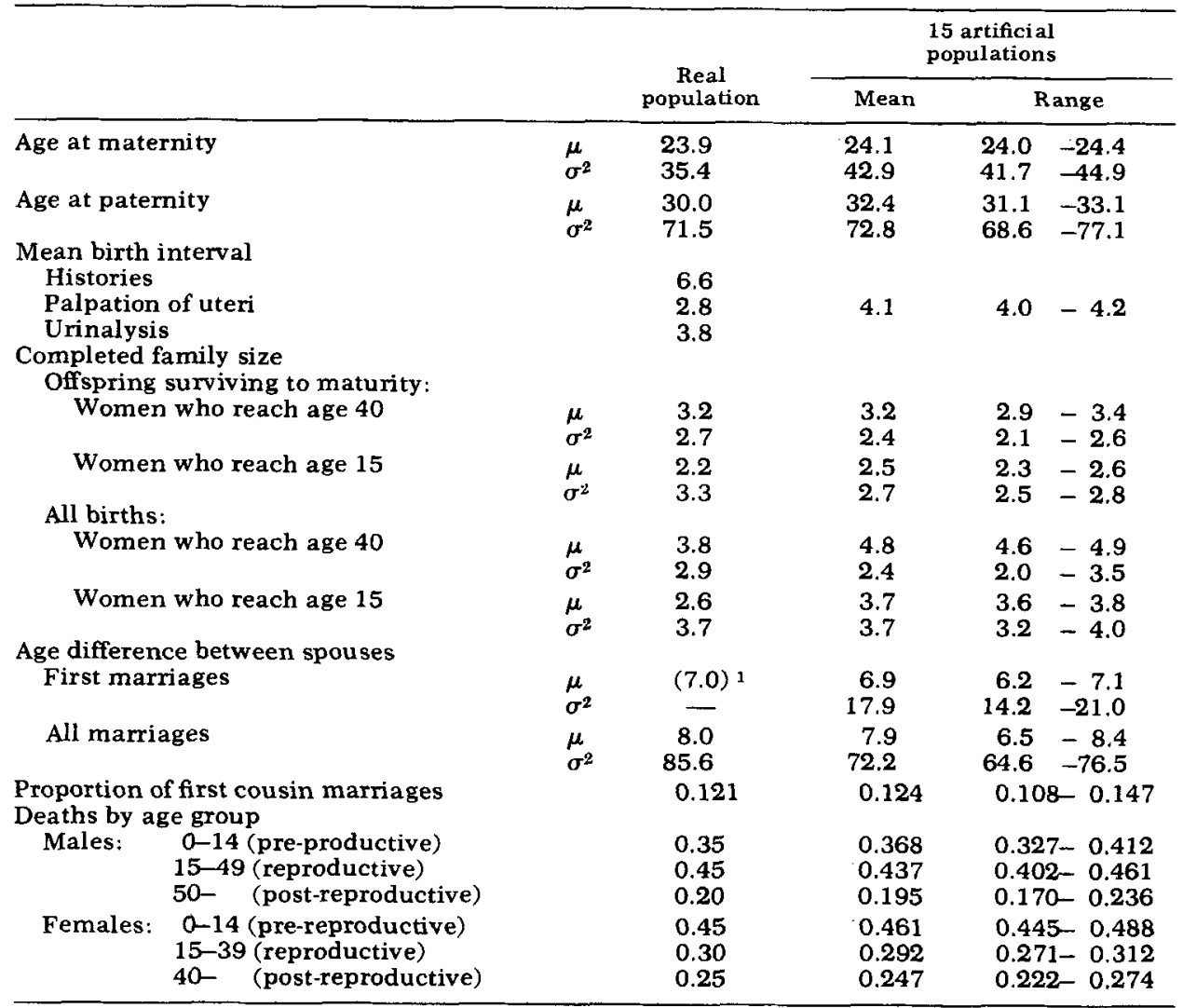

1 This figure is only a rough approximation, since few data are currently available on age at first marriage.

the intrinsic rate of increase (r), defined by

$$
{ }_{0}^{\infty} \mathrm{p}_{x} \mathrm{~b}_{x} \mathrm{e}^{-\mathrm{r} x} \mathrm{~d} x=1
$$

where $\mathbf{p}_{x}=$ probability of surviving to age $x$ and $\mathrm{b}_{x}=$ probability of reproducing at age $x$ (Lotka, '25). The intrinsic rate of increase calculated from the birth and death rates for the females in this population is 0.0311 . The great discrepancy between the intrinsic and actual growth rates may be attributed to a number of factors. First, the intrinsic rate of increase is a function of the age structure of the population, and is strictly applicable only to populations whose limiting age distribution has been reached (Tabah, '65). As seen in figure 1, in this particular case the age distribution of the initial population is quite irregular, with a bottleneck in the age group 10-19. In a large population, the stable age structure should be attained after the population has experienced about one hundred years of constant birth and death rates (Lopez, '61); however, in small populations, yearly fluctuations in numbers of births and deaths may make it extremely unlikely that the stable age distribution will ever be reached. Second, stable population theory does not take nuptiality into account. In populations for which marriage is a prerequisite for reproduction, random fluctuations in the age-sex distribution are likely to produce fluctuations in age-specific birth rates. Various attempts, none very successful, have been made to remedy this situation (Keyfitz, '68). We plan to explore in greater de- 
tail in a future paper the relationship between intrinsic and actual growth rates under varying fertility and mortality schedules, and with varying input age distributions.

Although the real and artificial populations are not alike in every detail, the overall correspondence between the two is good, the artificial populations resembling the real quite closely in most of the parameters listed (see table 4 ). The greatest discrepancies are in parameters which cannot be estimated very reliably in the real population: mean age at paternity and mean number of livebirths, both for women who complete reproduction and for those who survive at least to the beginning of the reproductive period. In the case of completed family size, women in the artificial populations have on the average one fewer livebirth than the ascertained number for women in the real population, but the pre-reproductive mortality (including infanticide) is also lower in the simulation, since the number of offspring surviving to maturity is approximately the same in the artificial and real populations. Thus, although we have not duplicated the real population precisely with respect to these two parameters (number of livebirths and pre-reproductive mortality), the discrepancies tend to cancel each other out. Mean birth interval has been estimated for the Yạnomamö in three ways: from individual reproductive histories, from palpation of the abdomen for an enlarged uterus, and from analysis of urine for the presence of chorionic gonadotrophins. Not surprisingly, the estimate based on histories is much larger than the other two; the estimate obtained from urinalysis is likely to be the most accurate, and is also close to the mean birth interval in the artificial populations.

The proportion of first cousin marriages was computed for the real population on the basis of all 124 marriages in the four villages, regardless of the amount of information available on ancestors. Mates were counted as first cousins if they had at least one grandparent in common. There were 15 such marriages in the initial population, seven of which were known to have only one common grandparent and two of which had either one or two, the identity of one of the grandparents being unknown. If the estimate used were based only on the 37 marriages in which all four grandparents of both spouses were known, the proportion of first cousin marriages would be $13 / 37=0.351$. The true proportion of first cousin marriages no doubt lies somewhere between these two extremes. A more extensive analysis of consanguinity in the Yanomamö will be presented elsewhere (MacCluer et al., in manuscript).

The range of values for the various parameters over all fifteen runs is shown in table 4. It is possible that in actual populations there are regulatory mechanisms that reduce variability. However, in view of the impossibility of collecting the necessary data in actual populations, we shall for the time being utilize the simulated values to give some indication of the variances of the underlying distributions, or of the amount of variability which might be expected in a series of actual populations subject to the same age-specific birth and death rates and possessing identical mating structures. Parameters which vary widely between runs will probably be less reliably estimated in actual populations than will parameters which fall within a narrow range. Thus, for the Yạnomamö, mean age at maternity and mean birth interval can probably be estimated more accurately from field data than mean age difference between spouses. Even such gross demographic measures as proportion of deaths before, during, and after the reproductive period vary considerably from run to run, in spite of the fact that the artificial populations have identical underlying vital rates.

Finally, there are certain properties of the actual population which can be studied more readily by simulation than by examining field data. The parameters listed in table 5 have been computed for the artificial populations but not for the real. Among the most interesting findings are that (1) in spite of a strong preference for village endogamy, $16.6 \%$ of males must leave their villages to find wives; and (2) recalling from table 4 that the frequency of first cousin marriages was $12.4 \%$, more than $37 \%$ of all marriages, exogamous as well as endogamous, in- 
TABLE 5

Some demographic characteristics of the artificial populations

\begin{tabular}{|c|c|c|c|c|}
\hline & & Mean & \multicolumn{2}{|c|}{ R ange } \\
\hline Frequency of village exogamy & & 0.166 & \multicolumn{2}{|c|}{$0.107-0.214$} \\
\hline \multicolumn{5}{|c|}{$\begin{array}{l}\text { Proportion completing reproductive } \\
\text { period without marrying }\end{array}$} \\
\hline $\begin{array}{cl}\text { Marriages by previous status } \\
\text { Males: } & \text { Single } \\
& \text { Widowed } \\
& 1 \text { wife } \\
& 2 \text { wives } \\
& 3 \text { wives }\end{array}$ & & $\begin{array}{l}0.442 \\
0.061 \\
0.268 \\
0.161 \\
0.068\end{array}$ & \multicolumn{2}{|c|}{$\begin{array}{l}0.411-0.516 \\
0.045-0.092 \\
0.245-0.286 \\
0.112-0.175 \\
0.035-0.092\end{array}$} \\
\hline $\begin{array}{ll}\text { Females: } & \text { Single } \\
\text { Widowed }\end{array}$ & & $\begin{array}{l}0.596 \\
0.404\end{array}$ & \multicolumn{2}{|c|}{$\begin{array}{ll}0.573- & 0.617 \\
0.383- & 0.427\end{array}$} \\
\hline $\begin{array}{l}\text { Proportion of second cousin } \mathrm{m} \\
\text { Among all marriages } \\
\text { Among first marriages }\end{array}$ & & $\begin{array}{l}0.247 \\
0.280\end{array}$ & \multicolumn{2}{|c|}{$\begin{array}{ll}0.218- & 0.281 \\
0.236- & 0.319\end{array}$} \\
\hline $\begin{array}{l}\text { Age at marriage } \\
\text { Males: } \quad \text { First marriages } \\
\text { All marriages }\end{array}$ & $\begin{array}{l}\mu \\
\sigma^{2} \\
\mu \\
\sigma^{2}\end{array}$ & $\begin{array}{l}18.8 \\
29.6 \\
25.0 \\
65.1\end{array}$ & $\begin{array}{l}18.1 \\
23.7 \\
23.5 \\
61.8\end{array}$ & $\begin{array}{l}-19.3 \\
-34.8 \\
-25.7 \\
-68.2\end{array}$ \\
\hline 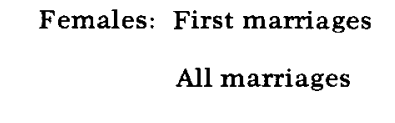 & $\begin{array}{l}\mu \\
\sigma^{2} \\
\mu \\
\sigma^{2}\end{array}$ & $\begin{array}{r}11.2 \\
4.2 \\
17.1 \\
80.1\end{array}$ & $\begin{array}{r}11.1 \\
2.7 \\
16.8 \\
77.0\end{array}$ & $\begin{array}{l}-11.3 \\
-5.9 \\
-17.6 \\
-85.6\end{array}$ \\
\hline
\end{tabular}

volve individuals related as first or second cousins. In some instances, e.g., the proportion of second cousin marriages, values from the actual population are virtually impossible to obtain and the simulated values may be used as reasonable estimates. For other parameters, e.g., age at marriage, the simulated figures may be verified eventually by the collection of additional data.

In the case of one parameter listed in table 5, the mean value from the simulations is obviously out of line: in the artificial populations nearly $30 \%$ of males who reach age 50 fail to marry. Although no estimate is available for the real population, our impression is that the proportion is much lower than this. The discrepancy is explained by the fact that males in the real population often separate from their wives, who then marry other men. As a result of this process, most men have a wife for at least a short time. The importance of this serial polyandry becomes apparent when one con templates the effect on Yanomamö social structure of such a high proportion of never-married males.

\section{Population structure: new interpretations}

The purpose of simulation is not merely to reproduce the real population, but to gain added insights. We present here three examples of such insights, with others to be discussed in subsequent papers.

(1) As mentioned earlier, we discovered at one point during the evolution of the model that the frequency of first cousin marriages in the artificial population was considerably lower than the frequency detectable in the real population, even though $70 \%$ of married couples in the four villages had insufficient pedigree depth to permit the detection of full first cousin marriages. In the process of altering the assumptions of the model to correct this situation, we gained considerable insight into Yạnomamö mating structure. We first changed the mating rules so that males looked for wives among their cousins before they began the pattern of searching by village and lineage, a change which seemed justified in view of the desirability of cross-cousin marriages 
among the Ya̧nomamö. But even when we imposed very strong preferences for cross-cousin marriage, the frequency of such marriages in the artificial population remained low compared to that observed in the field.

We concluded reluctantly that we were missing some important feature of Yanomamö population structure. If no amount of obligatory cousin marriage would produce in the model the high frequencies of consanguinity observed in the real population, then members of the real population must have been more closely related to each other than were those in the artificial population. This was in fact the case: Yanomamö males whose fathers are powerful (and therefore polygynous) are more likely to obtain extra wives (and children) themselves, with the result that a few men have many more grandchildren than the average, i.e., there are large groups of individuals who are related to each other as first cousins. Among 61 men in the four villages who were born before 1909, there are four who have $41,42,46$, and 62 grandchildren, respectively, Moreover, two of the men are fathers of the other two. For comparison, no female born before 1909 has more than 31 grandchildren. The fatherson correlation in fertility for 108 fatherson pairs in which the father was born before 1909 is 0.258 . Thus there is a sort of inheritance of fertility which can have important biological implications, especially in view of the fact that it is among the most powerful males in the population that polygyny is most common (Chagnon, unpublished). The model was subsequently modified so that prior to mating, both males and females whose fathers had many children were moved to the top of their respective mating arrays. This modification, together with the requirement that males look for wives first among their first and second cousins, was sufficient to produce a mean frequency of first cousin marriage consistent with that expected on the basis of the proportion observed in the actual population.

(2) The simulation suggests greater temporal variability in a number of important parameters than we had anticipated. For the parameters listed in table 6 , mean values were computed every ten years during the 200 years of each run. Table 6 gives the mean change in each parameter between successive ten year periods (or more precisely, the mean of the absolute value of the change), as well as the maximum change. The stability of these parameters through time in both the real and the artificial populations varies in part as a function of how simply they are related to underlying vital rates and how sensitive they are to interactions between the sexes. For example, mean age at paternity, the most variable of the parameters listed, is only indirectly related to the input vital rates, being affected in a complex way by the age structure of the population, by probabilities of reproducing for females and by the distribution of age differences between spouses. On the other hand, mean age at maternity, which is less variable, is a function almost exclusively of female reproductive rates and depends very little on mating structure. In general, the results shown in table 6 are consistent with those in the last column of table 4 .

It became evident during our experimentation with the model that although the proportion of first (and second) cousin marriages characterizing the entire 200 years of simulation was not extremely variable between runs, there were wide fluctuations through time in each artificial population and, presumably, in the real population as well. Thus, if we consider the difference between frequencies of first cousin marriages in successive ten-year periods, the distribution of such differences over all fifteen runs is shown in figure 4 . The mean difference is, of course, near zero (0.0003), with a standard deviation of 0.048 . If we are concerned rather with the absolute value of the difference, the mean is 0.038 with a standard deviation of 0.028 . The maximum difference of 0.153 occurred when the proportion of first cousin marriages dropped from 0.216 in one ten-year period to only 0.063 in the next, these proportions being based on 74 and 79 marriages, respectively. If we consider instead marriages occurring in a 30-year period and compute the frequency of cousin marriages every ten years, so that there is a turnover rate of one-third of the marriages in each ten-year period, 
TABLE 6

Changes in parameter estimates in a ten-year period

\begin{tabular}{lccc}
\hline Parameter & \multicolumn{3}{c}{ Absolute value of change } \\
\cline { 2 - 4 } & $\mu$ & $\sigma$ & Maximum \\
\hline Age at maternity & 0.692 & 0.584 & 3.21 \\
Age at paternity & 1.053 & 0.826 & 3.60 \\
Birth interval & 0.297 & 0.242 & 1.20 \\
Completed family size & & & \\
$\quad$ Surviving offspring & & & \\
$\quad$ Females > 40 & 0.389 & 0.321 & 1.72 \\
$\quad$ Females > 15 & 0.299 & 0.232 & 1.39 \\
Livebirths & & & \\
$\quad$ Females > 40 & 0.415 & 0.331 & 2.50 \\
Females > 15 & 0.320 & 0.289 & 1.88 \\
\hline
\end{tabular}

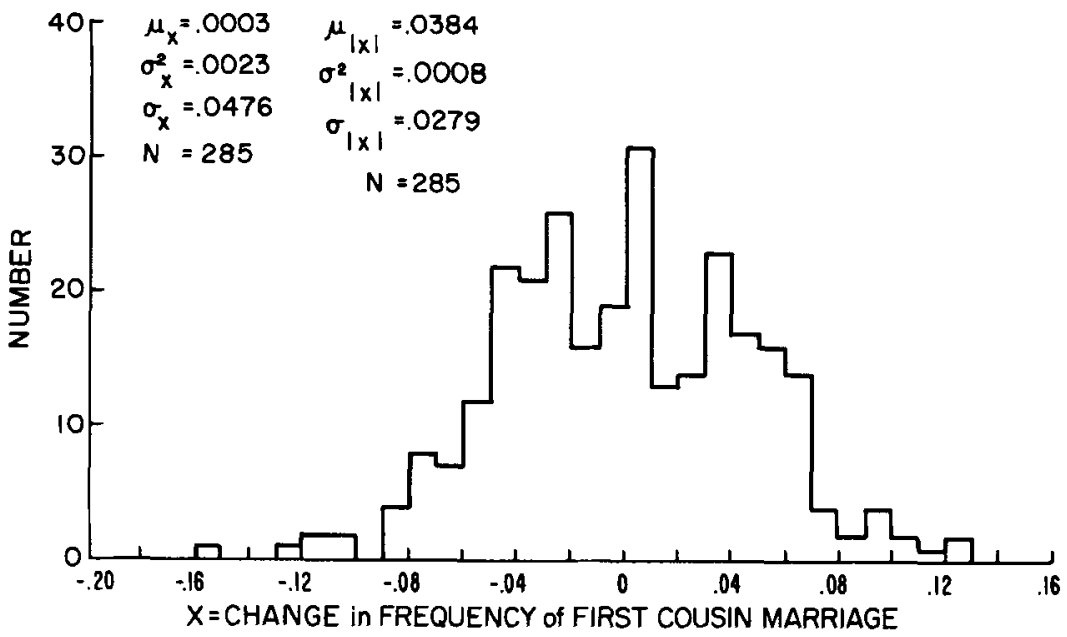

Fig. 4 Distribution of the change in frequency of first cousin marriages between successive ten-year time periods, for fifteen 200 -year simulation runs. $\mu$, mean change in frequency; $\sigma_{\mathrm{X}}{ }^{2}$, variance in change; $\sigma_{\mathrm{X}}$, standard deviation of change; $\mu_{\mathrm{X}}$, mean of absolute value of change; $N$, total number of ten-year time periods.

then the absolute value of the change is of course dampened, with a mean value of 0.015 , a standard deviation of 0.011 , and a maximum of 0.054 . However, it is unlikely that there would be available in a primitive population accurate data on the relatedness of married couples over a 30-year period. The magnitude of these fluctuations was unexpected; it is obvious that one must be cautious in the significance one attaches to the proportion of first cousin marriages observed at any specific time. We would like to determine whether the variability shown in the model is also found in real populations. This will be ascertained by a comparison of frequencies of consanguineous marriage from one village cluster to the next. If the real population is found to be less variable than the model in frequencies of consanguinity, then it may be inferred that there are in the actual society regulatory devices not present in the model.

(3) A final aspect of Yanomamö population structure which was clarified by these simulations concerns the population growth rate. The ethnographic data indicate that during the past 100 years the Yanomamö have extended their distribution significantly, this extension accompanied by a proliferation of villages (Chagnon, '68c; Ward, '70). Unless mean village size has decreased, this implies an increase in population numbers. When the raw demographic data were first presented (Neel and Chagnon, '68), it was 
by no means clear that these were con sistent with an expanding population. The fact that the simulation output indicates a population increase roughly comparable to that suggested by the ethnographic data not only gives confidence in the output but reinforces the ethnographic data. Elsewhere (Neel, in press), we have suggested that a primary factor in this expansion may have been the postColumbian acquisition of the cooking banana (Musa paradisiaca), this playing the role here of the potato when introduced into Europe in the mid-eighteenth century.

\section{CONCLUSIONS}

The potential value of computer simulation in the study of primitive populations has not been fully appreciated. Computer models provide (1) a means of assessing the stability and reliability of various routinely collected demographic data; (2) a procedure for estimating certain parameters which cannot be estimated from the data alone because of insufficient time depth; (3) a tool for discovering inconsistencies in the data; and (4) a method for testing hypotheses about small population structure.

Simulation models may be used not only in the study of specific populations, but also as a means of arriving at generalizations about population structure. For, example, we are investigating the relationship between intrinsic and actual growth rates under a variety of fertility and mortality schedules and input age distributions in the hope of establishing a general pattern. The computer model will also be used to examine the degree of relatedness between populations, the simulated results being compared with the predictions of several theoretical models (Wright, '65; Hiorns et al., '69). In these ways, we are using computer simulation to test the appropriateness of particular mathematical models, i.e., to determine whether the simplifying assumptions of the models limit the validity of their predictions.

\section{ACKNOWLEDGMENTS}

We wish to thank Dr. William J. Schull and Dr. Bennett Dyke for helpful criticism of the manuscript.

\section{LITERATURE CITED}

Anderson, W. W., and C. E. King 1970 Agespecific selection. Proc. Nat. Acad. Sci, 66: 780-786.

Beshers, J. M. 1967 Computer models of social processes: The case of migration. Demography, 4: 838-842.

Brues, A. M. 1963 Stochastic tests of selection in the ABO blood groups. Am. J. Phys. Anthrop., 21: 287-299.

Cavalli-Sforza, L. L. 1969 "Genetic drift" in an Italian population. Sci. Am., 221 (2): 30-37.

Cavalli-Sforza, L. L., and G. Zei 1967 Experiments with an artificial population. In: Proceedings IIIrd International Congress of $\mathrm{Hu}$ man Genetics. J. F. Crow and J. V. Neel, eds. Johns Hopkins Press, Baltimore, pp. 473-478

Chagnon, N. A. 1966 Yạnomamö Warfare, Social Organization and Marriage Alliances. (Ph.D. Thesis) University of Michigan, Ann Arbor.

1968a Yạnomamö social organization and warfare. In: War: The Anthropology of Armed Conflict and Aggression. M. Fried, M. Harris and R. Murphy, eds. Natural History Press, Garden City, pp. 109-159.

1968b Ya̧nomamö: The Fierce People Case Studies in Cultural Anthropology. Holt Rinehart and Winston, New York.

$1968 \mathrm{c}$ The culture-ecology of shifting (pioneering) cultivation among the Yanomamö Indians. In: Ecology in Anthropological and Ethnological Man-Culture-Habitat Relationships. VIIIth International Congress of Anthropological and Ethnological Sciences, Tokyo, Vol. III: 249-255.

Coale, A. J., and P. Demeny 1966 Regional Model Life Tables and Stable Populations. Princeton.

Dyke, B, 1968 Numbers of Potential Mates in a Small Human Population. (Ph.D. Thesis) University of Michigan, Ann Arbor.

Gilbert, J. P., and E. A. Hammel 1966 Computer simulation and analysis of problems in kinship and social structure. Am. Anthropol., 68: 71-93.

Hainline, J. 1963 Genetic exchange: Model construction and a practical application. Human Biol., 35: 167-191.

Heer, D. M., and D. O. Smith 1968 Mortality level, desired family size, and population increase. Demography, 5: 104-121.

1969 Mortality level, desired family size and population increase: Further variations on a basic model. Demography, 6: 141149.

Hiorns, R. W., G. A. Harrison, A. J. Boyce and C. F. Kuchemann 1969 A mathematical anal$y$ sis of the effects of movement on relatedness between populations. Ann. Hum. Genet., 32: 237-250.

Hyrenius, H. 1965 New Technique for Studying Demographic-Economic-Social Interrelations. Demographic Institute, University of Göteborg, Sweden. Reports 3.

Hyrenius, H., and I. Adolfsson 1964 A Fertility Simulation Model. Demographic Institute, University of Göteborg, Sweden. Reports 2. 
Hyrenius, H., I. Adolfsson and I. Holmberg 1966 Demographic Models. Demographic Institute University of Göteborg, Sweden. Reports 4.

Hyrenius, H., I. Holmberg and M. Carlsson 1967 Demographic Models. Demographic Institute, University of Göteborg, Sweden. Reports 5.

Jacquard, A. 1967 La reproduction humaine en régime malthusien. Un modèle de simulation par la méthode de Monte Carlo. Population, 22: 897-920.

1970 Panmixie et structure des familles. Population, 25: 69-76.

Jain, A. K. 1968 Predicting duration specific averages and variances of live births: Application of a stochastic model of human reproduction. Proc. Am. Stat. Assoc., 1968: 248-255.

Keyfitz, N. 1968 Introduction to the Mathematics of Population. Addison-Wesley.

King, C, E., and W. W. Anderson 1971 Age specific selection. II. The interaction between " $r$ " and " $K$ " during population growth. Am. Naturalist, 105: 137-156.

Kunstadter, $P$ R. Buhler, F, F. Stephan and C. F. Westoff 1963 Demographic variability and preferential marriage patterns. Am. J. Phys. Anthrop., 21: 511-519.

Levin, B. R. 1967 The effect of reproductive compensation on the long term maintenance of the $\mathrm{Rh}$ polymorphism: The $\mathrm{Rh}$ crossroad revisited. Amer. J. Hum. Genet., 19: 288--302.

Livingstone, F. 1969 The founder effect and deleterious genes. Am. J. Phys. Anthrop., 30 55-60.

Lopez, A. 1961 Problems in Stable Population Theory. Office of Population Research, Princeton.

Lotka, A. J. 1925 On the true rate of natural increase. J. Ar.. Stat. Assoc., 20: 305-339.

MacCluer, J. W. 1967 Monte Carlo methods in human population genetics: A computer model incorporating age-specific birth and death rates. Amer. J. Hum. Genet., 19: 303312.

MacCluer, J. W., and W. J. Schull 1970a Frequencies of consanguineous marriage and ac- cumulation of inbreeding in an artificial population. Amer. J. Hum. Genet, 22: 160-175.

$1970 \mathrm{~b}$ Estimating the effective size of human populations. Amer. J. Hum. Genet., 22: 176-183.

Morgan, K. 1969 Monte Carlo simulation of artificial populations: The survival of small closed populations. Conference on the Mathematics of Population, Berkeley and Asilomar, Calif.

Neel, J. V. The genetic structure of a tribal population, the Yanomamö Indians. I. Introduction. Ann. Hum. Genetics, in press.

Neel, J. V., and N. A. Chagnon 1968 The demography of two tribes of primitive, relatively unacculturated American Indians. Proc. Nat. Acad. Sci., 59: 680-689.

Orcutt, G. H., M. Greenberger, J. Korbel and A. M. Rivlin 1961 Microanalysis of Socioeconomic Systems: A Simulation Study. Harper and Row, New York.

Perrin, E. B., and M. C. Sheps 1964 Human reproduction: A stochastic process. Biometrics, 20: $28-45$.

Schull, W. J., and B. R. Levin 1964 Monte Carlo simulation: Some uses in the genetic study of primitive man. In: Stochastic Models in Medicine and Biology. J. Gurland, ed. University of Wisconsin Press, Madison, pp. 179 196.

Tabah, L. 1965 Relationships between age structure, fertility, mortality, and migration. Population replacement and renewal. UN World Population Conference, Belgrade, 9: 292-339.

Ward, R. H. 1970 Micro-differentiation and Genetic Relationships of Yanomamö Villages. (Ph.D. Thesis) University of Michigan, Ann Arbor.

Williams, 8. J. 1965 A Model of Hunting. Gathering Society and Some Genetic Consequences. (Ph.D. Thesis) University of Michigan, Ann Arbor.

Wright, S. 1965 The interpretation of population structure by $F$ statistics with special regard to systems of mating. Evolution, 19: 395420 . 